\title{
Pellon fosforitalouden agroekologinen parantaminen tavanomaisessa viljelyssä
}

\author{
Into Saarela $^{1)}$ ja Martti Vuorinen ${ }^{2)}$ \\ ${ }^{1)}$ Maa- ja elintarviketalouden tutkimuskeskus,31600 Jokioinen, into.saarela@mtt.fi \\ ${ }^{2)}$ Maa- ja elintarviketalouden tutkimuskeskus, Hämeen tutkimusasema, \\ Myttääläntie 213, 36600 Pälkäne, martti.vuorinen@mtt.fi
}

\section{Johdanto}

Viljelyn kehittäminen fosforin osalta nykyistä ympäristöystävällisemmäksi muutenkin kuin säätelemällä pellon fosforitasetta tai torjumalla eroosiota ovat jääneet keskustelussa vähälle huomiolle. Fosfaatti-ionien tehokas pidättyminen Suomen maaperään ja erittäin hidas liikkuminen antavat kuitenkin mahdollisuuksia kehittää pellon fosforitaloutta nimenomaan tavanomaisen viljelyn menetelmillä. Maan fosforivarojen tehokas käyttö edellyttää peltojen kalkitsemista riittävästi mutta ei liikaa. Jokioisissa lievästi happaman savimaan runsas kalkitus ( $\mathrm{pH}$ 6.0:sta yli 6.5:een, Saarela et al. 2000) paransi myös nurminata-timoteinurmen fosforin saantia ja kasvua vuosina 1999-2001. Nurmiheinien ei ole arveltu hyötyvän näin viljavien petojen kalkituksesta lainkaan, mutta aikaisemmat käsitykset eivät ole perustuneet tutkimuksiin. Muita fosforin saantiin ja lannoitustarpeeseen vaikuttavia maaperätekijöitä ovat maan vesitalous ja rakenne sekä lannoitetun maan tilavuus ja sijainti juuriin nähden, jotka riippuvat lannoitus- ja muokkausmenetelmistä.

Koska fosforia kulkeutuu kasvukauden aikana vain noin kymmenen millimetrin päähän lannoiterakeista (Saarela ja Saarela 2000), juurten pitää kasvaa hyvin lähelle lannoiterivejä saadakseen niistä fosforia (Saarela 1996). Pitkinä poutakausina, jolloin koko lannoitettu ruokamultakerros voi kuivua ja estää fosforin saannin, lannoitetun ruokamullan ja fosforilannoitteen multaaminen tavallista kyntöä syvemmälle voisi olla edullista (Saarela et al. 2000). Tässä esityksessä tarkastellaan fosforilannoitteen sijoittamisen ja multaussyvyyden vaikutuksia viljasatoon Jokioisten savimailla ja Pälkäneen hietamaalla tehtyjen kenttäkokeiden perustella.

\section{Aineisto ja menetelmät}

Erilaisia lannoitteiden ja siementen sijoittamistapoja tutkittiin vuosina 1997-1998 viidellä koepaikalla: Vihdin hietasavella ( $\mathrm{pH} \mathrm{6,4} \mathrm{ja} \mathrm{P} \mathrm{6,3} \mathrm{mg/l),} \mathrm{Mietoisten} \mathrm{aitosavella} \mathrm{(} \mathrm{pH} \mathrm{6,4} \mathrm{ja} \mathrm{P} \mathrm{8,8} \mathrm{mg/l),} \mathrm{Jokioisten}$ runsasmultaisella liejusavella (pH 5,4 ja P 4,9 mg/l), Pälkäneen karkealla hiedalla (pH 6,1 ja P 6,2 mg/l) ja Jokioisten niukkafosforisella savimaalla monivuotisessa kokeessa, jonka pH-luku oli 6,3 ja asetaattiliukoisen fosforin pitoisuus vaihteli vuodesta 1992 jatkuneen lannoituksen mukaan 0,9:sta 2,4 mg:aan/l. Vihdin ja Mietoisten viljavilla savimailla fosforin saanti ei rajoittanut kasvua.

Kokeissa verrattiin normaalin sijoituslannoituksen lisäksi kolmea muuta siementen ja lannoitteiden sijoitustapaa: erillisen fosforilannoitteen sijoittamista siemenriveihin starttilannoituslaitteella, lannoiterivien levittämistä nauhaksi siipimäisillä lannoitevantailla ja siemenrivien siirtämistä pareittain lähemmäksi lannoiterivejä. Kylvölannoitusmenetelmien ja lannoitteiden fosforimäärien yhdistelmiä oli kaikkiaan kymmenen. Toisena koekäsittelynä oli jyräys kaistoittain kahtena kerranteena (1997) tai lannoiterivien tiivistäminen ylimääräisillä jyräpyörillä puolella kylvölannoittimen leveydestä (1998).

Fosforilla rikastelun kerroksen syventämistä on tutkittu Jokioisissa alustavilla kokeilla vuodesta 1993 lähtien. Aluksi käytettiin tavallista syväkyntöauraa, ja vuodesta 1996 alkaen syväkyntölaitetta, jolla maan pintaan jää yhtenäinen kerros alkuperäistä ruokamultaa (Saarela et al. 2000). Vuosina 1999-2001 tukittiin syvämultauksen ja starttilannoituksen yhdistämistä niukkafosforisella maalla.

\section{Tulokset ja tarkastelu \\ Lannoitusmenetelmät}

Niistä starttilannoituskokeista, joissa fosforin saanti rajoitti kasvua, esitetään tuloksia taulukoissa 1-4. Jokioisten runsasmultaisen liejusaven viljavuus oli välttävä sekä happamuuden että fosforin suhteen. Fosforilannoituksen selvä vaikutus kauran oraiden kasvuun ja tilastollisesti epävarma, vähäinen vaikutus jyväsatoon olivat siten odotettavissa (Taulukko 1). Jyräys nopeutti kauran alkukehitystä selvästi, mutta ei lisännyt jyväsatoa. Vuonna 1998 kokeessa viljellyn ohran kasvua haittasi orasvaiheessa liikamärkyys. Tällöin normaaliin tapaan yli kuuden senttimetrin syvyyteen sijoitettu fosfori oli kokonaan juurten ulottumattomissa, mutta siemenriviin sijoitetun starttifosforin ja tavallista matalampaan nauhaksi sijoitetun lannoitteen fosforin ottoa märkyys ei täysin estänyt. Ohra kasvoi 
näillä matalilla lannoituksilla selvästi paremmin kuin syvemmillä fosforin sijoituksilla, jotka eivät selvästi erottuneet pelkällä NK:lla lannoitetusta verranteesta. Matalaan sijoitetun fosforin paremmuus pysyi suurehkona tuleentumiseen saakka. Samankaltainen tulos saatiin Jokioisissa jo aikaisempana sateisena keväänä vuonna 1995 (Saarela 1996).

Taulukko 1. Lannoitteen ja siementen sijoittamisen ja jyräyksen vaikutus kauran (1997) ja ohran (1998) kasvuun ja jyväsatoon Jokioisten runsasmultaisella liejusavella. Lannoitusmenetelmät: $\mathrm{V}=$ normaali kylvölannoitus; $\mathrm{S}=$ startti-P-lannosta siemenriveihin; $\mathrm{LS}=$ lannoite $\mathrm{n} .7 \mathrm{~cm}$ leveäksi nauhaksi; $\mathrm{SS}=$ siemenet kylvetty pareittain lähemmäksi lannoiterivejä. Typpilannoitus 80 kg/ha (400 kg/ha NK 20-0-15, NPK 20-3-12 tai NPK 20-5-4).

\begin{tabular}{|c|c|c|c|c|c|c|}
\hline \multirow{2}{*}{$\begin{array}{l}\text { Sijoitus- } \\
\text { tapa }\end{array}$} & \multirow{2}{*}{$\begin{array}{l}\text { P-lannoitus } \\
\text { kg/ha }\end{array}$} & \multicolumn{2}{|c|}{20 oraan paino 1997, g } & \multicolumn{2}{|c|}{ Jyväsato $1997, \mathrm{~kg} / \mathrm{ha}$} & \multirow{2}{*}{$\begin{array}{l}\text { Jyväsato 1998, kg/ha } \\
\text { Ei jyr. jyrätty keskim. }\end{array}$} \\
\hline & & Ei jyr. & Jyrätty & Ei jyr. & Jyrätty & \\
\hline $\mathrm{V}$ & 0 & 2.30 & 2.58 & 3990 & 3850 & 2260 \\
\hline $\mathrm{V}+\mathrm{S}$ & $0+8$ & 2.82 & 3.13 & 4090 & 4020 & 2738 \\
\hline $\mathrm{V}$ & 12 & 2.34 & 2.88 & 3920 & 3930 & 2255 \\
\hline SS & 12 & 2.82 & 3.23 & 4210 & 4090 & 2360 \\
\hline LS & 12 & 2.37 & 2.96 & 4100 & 3980 & 2479 \\
\hline $\mathrm{V}+\mathrm{S}$ & $12+8$ & 2.59 & 3.16 & 4030 & 3880 & 2852 \\
\hline $\mathrm{V}$ & 20 & 2.57 & 3.10 & 4030 & 3880 & 2367 \\
\hline SS & 20 & 2.64 & 3.29 & 3770 & 3930 & 2087 \\
\hline LS & 20 & 2.30 & 2.93 & 4170 & 4170 & 2580 \\
\hline $\mathrm{V}+\mathrm{S}$ & $20+8$ & 2.59 & 3.17 & 4100 & 4070 & 2732 \\
\hline
\end{tabular}

Taulukko 2. Lannoitteen ja siementen sijoittamisen ja jyräämisen vaikutus ohran oraiden fosforin saantiin ja jyväsatoon Pälkäneen hietamaalla. Lannoitus kuten taulukossa 1. Vuoden 1998 tulokset ovat jyräämättömän ja jyrätyn keskiarvoja.

\begin{tabular}{|c|c|c|c|c|c|c|c|}
\hline \multirow{2}{*}{$\begin{array}{l}\text { Sijoitus- } \\
\text { tapa }\end{array}$} & \multirow{2}{*}{$\begin{array}{l}\text { P-lannoitus } \\
\text { kg/ha }\end{array}$} & \multicolumn{2}{|c|}{ Oraiden P 1997, kg/ha } & \multicolumn{2}{|c|}{ Jyväsato 1997, kg/ha } & \multicolumn{2}{|c|}{ Keskim. 1998, kg/ha } \\
\hline & & Ei jyr. & Jyrätty & Ei jyr. & Jyrätty & Orassato & Jyväsato \\
\hline $\mathrm{V}$ & 0 & 1.21 & 1.62 & 4390 & 4340 & 1.35 & 3240 \\
\hline $\mathrm{V}+\mathrm{S}$ & $0+8$ & 2.16 & 2.33 & 4780 & 4780 & 2.73 & 3960 \\
\hline $\mathrm{V}$ & 12 & 2.48 & 2.85 & 4780 & 4590 & 2.70 & 4220 \\
\hline SS & 12 & 2.84 & 3.24 & 5140 & 4970 & 2.69 & 4200 \\
\hline LS & 12 & 2.22 & 2.42 & 4660 & 4680 & 2.90 & 4030 \\
\hline $\mathrm{V}+\mathrm{S}$ & $12+8$ & 2.69 & 3.42 & 4830 & 4830 & 3.26 & 4120 \\
\hline $\mathrm{V}$ & 20 & 3.33 & 3.80 & 4840 & 4640 & 3.41 & 4270 \\
\hline SS & 20 & 3.60 & 3.75 & 4750 & 4810 & 3.35 & 4230 \\
\hline LS & 20 & - & - & - & - & 3.18 & 4290 \\
\hline $\mathrm{V}+\mathrm{S}$ & $20+8$ & 3.31 & 3.60 & 4770 & 4680 & 3.29 & 4160 \\
\hline
\end{tabular}

Pälkäneen karkealla hiedalla fosforilannoitus vaikutti ohran kasvuun ja satoon enemmän kuin näin viljavalla ja hyvärakenteisella maalla yleensä, mutta sadon maksimi saavutettiin aika pienillä fosforimäärillä (Taulukko 2). Lannoitusmenetelmistä oli paras tavallinen kylvölannoitus joko normaaliin etäisyyteen tai hiukan lähemmäksi siemeniä sijoitettuna. Fosforilannoitteen lisääminen siemenriveihin ei ollut merkittävästi huonompi, kuten oli lannoitteen hajottaminen leveäksi nauhaksi. Vuonna 1998 viljellyn suurijyväisen Inari-ohran (tuhannen siemenen paino yli $50 \mathrm{~g}$ ) fosforipitoisuus oli hiukan tavallista matalampi, vain runsaat $3 \mathrm{~g} / \mathrm{kg}$. Molempina vuosina fosforilannoituksen lisääminen paransi oraiden kasvua, samoin jyrääminen vuonna 1997, mutta eivät jyräpyörät sateisena vuonna 1998. Jyväsato ei parantunut kumpanakaan vuonna samassa suhteessa kuin oraiden kasvu. 
Jokioisten niukkafosforisella savella jyrääminen paransi vuonna 1997 ohran oraiden kasvua ja pienensi sadon puintikosteutta, mutta ei suurentanut sadon määrää kuten ei muissakaan kokeissa (Taulukko 3). Lannoitusmenetelmien välillä ei ollut suuria eroja, mutta tavallinen sijoitustapa ja pareittain lähemmäksi lannoiterivejä kylvetyt siemenrivit näyttivät taas parhailta. Lopullisen jyväsadon kannalta tärkeimmäksi tekijäksi osoittautui vuodesta 1992 jatkuneen fosforilannoituksen määrä. Fosforimäärä $42 \mathrm{~kg} / \mathrm{ha}$ ja maan P $2.4 \mathrm{mg} / \mathrm{l}$ kasvatti $600 \mathrm{~kg} / \mathrm{ha}$ suurempia satoja kuin fosforilannoitus $18 \mathrm{~kg} / \mathrm{ha}$ ja maan P $1.4 \mathrm{mg} / \mathrm{l}$. Pelkkään NK-lannoitukseen verrattuna suurimman fosforimäärän vaikutus hehtaarisatoon oli pari tonnia, mutta maan liukoisen fosforin pitoisuuteen 0.9 $\mathrm{mg} / \mathrm{l}$ nähden ilman fosforilannoitusta saatu lähes neljän tonnin sato ei ollut huono.

Taulukko 3. Lannoitteen ja siementen sijoittamisen vaikutus ohran kasvuun, jyväsatoon ja puintikosteuteen Jokioisten niukkafosforisella savimaalla vuonna 1997 Lannoitusmenetelmät kuten taulukossa 1. Typpilannoitus 120 kg/ha (600 kg/ha NK 20-0-15, NPK 20-3-12 tai 706 kg/ha NPK 17-6-10).

$\begin{array}{llllll}\begin{array}{l}\text { Sijoitus- } \\ \text { tapa }\end{array} & \begin{array}{l}\text { P-lann. } \\ \text { kg/ha }\end{array} & \begin{array}{l}\text { 20 oraan paino, g } \\ \text { Ei jyr. Jyrätty }\end{array} & \begin{array}{l}\text { Jyväsato, kg/ha } \\ \text { Ei jyr. Jyrätty }\end{array} & \begin{array}{l}\text { Puintikosteus, \% } \\ \text { Ei jyr. Jyrätty }\end{array} & \begin{array}{l}\text { Maan P, mg/l } \\ \text { Keskimäärin }\end{array}\end{array}$

\begin{tabular}{lllllllll}
\hline & & & & & & & \\
$\mathrm{V}$ & 0 & 1.04 & 1.21 & 3750 & 3590 & 25.3 & 17.9 & 0.9 \\
$\mathrm{~V}+\mathrm{S}$ & $0+24$ & 1.38 & 1.81 & 5170 & 5060 & 15.5 & 12.0 & 1.4 \\
$\mathrm{~V}$ & 18 & 1.58 & 2.04 & 5170 & 4970 & 14.9 & 11.6 & 1.4 \\
$\mathrm{SS}$ & 18 & 1.63 & 2.06 & 5150 & 5000 & 14.2 & 12.0 & 1.4 \\
$\mathrm{LS}$ & 18 & 1.54 & 1.92 & 5070 & 4850 & 14.9 & 11.9 & 1.4 \\
$\mathrm{~V}+\mathrm{S}$ & $18+24$ & 1.89 & 2.26 & 5840 & 5730 & 14.6 & 11.3 & 2.4 \\
$\mathrm{SS}$ & 42 & 2.04 & 2.35 & 5800 & 5660 & 13.5 & 11.1 & 2.4 \\
$\mathrm{LS}$ & 42 & 1.61 & 2.20 & 5660 & 5460 & 13.3 & 11.5 & 2.4 \\
\hline
\end{tabular}

Taulukko 4. Lannoitteen ja siementen sijoittamisen vaikutus syysvehnän kasvuun, fosforin saantiin ja jyväsatoon Jokioisten niukkafosforisella savimaalla vuonna 1998 Lannoitusmenetelmät kuten taulukossa 1. Typpilannoitus 40+110 kg/ha (200 kg/ha NK 20-0-15, 235 kg/ha NPK 17-6-10 tai 500 kg/ha NPKkv 8-10-12).

\begin{tabular}{|c|c|c|c|c|c|c|c|c|c|}
\hline \multirow{2}{*}{$\begin{array}{l}\text { Sijoitus- } \\
\text { tapa }\end{array}$} & \multirow{2}{*}{$\begin{array}{l}\text { P-lann. } \\
\text { kg/ha }\end{array}$} & \multicolumn{2}{|c|}{ Oraiden ka kg/ha } & \multicolumn{2}{|c|}{ Or. P-pit. g/kg } & \multicolumn{2}{|c|}{ Or. P:n otto kg/ha } & \multirow{2}{*}{$\begin{array}{l}\text { Jyväsato } \\
\text { kg/ha }\end{array}$} & \multirow{2}{*}{$\begin{array}{l}\text { Maan P } \\
\text { mg/l }\end{array}$} \\
\hline & & 1 & 2 & 1 & 2 & 1 & 2 & & \\
\hline $\mathrm{V}$ & 0 & 370 & 680 & 1.44 & 1.84 & 0.54 & 1.25 & 3400 & 0.9 \\
\hline $\mathrm{V}+\mathrm{S}$ & $0+16$ & 830 & 1960 & 2.61 & 1.94 & 2.17 & 3.82 & 4940 & 1.4 \\
\hline $\mathrm{V}$ & 14 & 700 & 1620 & 2.67 & 2.10 & 1.88 & 3.41 & 4440 & 1.4 \\
\hline SS & 14 & 740 & 1680 & 2.73 & 2.02 & 2.02 & 3.40 & 4440 & 1.4 \\
\hline LS & 14 & 760 & 1720 & 2.71 & 2.03 & 2.05 & 3.49 & 4480 & 1.4 \\
\hline V & 50 & 840 & 2260 & 3.66 & 2.49 & 3.07 & 5.63 & 4960 & 2.4 \\
\hline SS & 50 & 860 & 2310 & 3.52 & 2.58 & 3.02 & 5.95 & 4720 & 2.4 \\
\hline LS & 50 & 860 & 2140 & 3.62 & 2.60 & 3.12 & 5.54 & 4850 & 2.4 \\
\hline
\end{tabular}

Vuonna 1998 viljeltyä syysvehnää ei jyrätty. Lannoituksen vaikutukset satoon olivat muuten samankaltaisia kuin ohralla, mutta siemenriveihin sijoitettu fosfori oli muita lannoitustapoja tehokkaampaa (Taulukko 4). Starttifosforilannoitus $16 \mathrm{~kg} / \mathrm{ha}$ tuotti maksimaalisen sadon, vaikka maan fosforiluku oli vain $1.4 \mathrm{mg} / \mathrm{l}$. Tämän käsittelyn hyvä teho näkyi kasvustossa keväällä heti kasvun alkaessa ja sen paremmuus säilyikin korjuuseen saakka, vaikkei oraiden fosforipitoisuuksissa vaikutusta enää löytynyt ensimmäisissäkään orasnäytteissä. Siemenriviin sijoitettu fosfori oli tehokasta maan pinnan ollessa vielä kosteaa ja lämpimämpää kuin syvemmällä. Tiiviimmissä syysviljamaissa ei myöhemminkään ole samanlaista löyhää, ilmakuivaa kerrosta kuin keväällä äestetyissä savimaissa, joiden pinta on kuivina alkukesinä juureton useiden senttimetrien syvyyteen saakka. Parilliset siemenrivit eivät tuottaneet runsaalla lannoituksella tilastollisesti merkitsevästi pienempää satoa, mutta yhdessä aikaisempien samansuuntaisten trendien kanssa tulos viittaa siihen, että vähäinenkin 
siemenrivien parillisuus heikentää kasvutilan hyväksikäyttöä ja satoa olosuhteiden ollessa muuten samanlaiset.

\section{Fosforin multaussyvyys}

Syksyllä 1998 mullattu fosfori yritettiin saada kokonaan yli $25 \mathrm{~cm}: n$ syvyyteen (Saarela et al. 2000), minne se maa-analyysien mukaan pääosin sijoittuikin (Taulukko 5). Syksyllä 1999 ja 2000 koe kynnettiin hiukan tavallista matalampaan, jotta $36 \mathrm{~cm}: n$ syvyyteen mullatun vajaan $10 \mathrm{~cm}: \mathrm{n}$ ruokamultakerroksen päälle noussutta jankkoa ei sekoittuisi liikaa maan pintaan. Kokonaan samalla tavalla muokatun kokeen tuloksia voitiin verrata sen vieressä tavanomaisella muokkauksella saatuihin tuloksiin. Kuivana kesänä 1999 myöhään kylvetty kaura kasvoi huonosti, mutta syvämultauksella saatiin jopa kaksinkertaisia satoja normaaliin kyntöön verrattuna. Vuoden 2000 keskinkertaiset ohrasadot vaihtelivat aika vähän eri lannoitusten välillä.

Vuonna 2001 ohrasadot muodostuivat aikaisempia runsaammiksi ja toisin kuin ennen, kasvoivat suurimpaan lannoitukseen saakka. Nämä satotulokset ja maa-analyysit viittaavat siihen, fosforin syvämultauksen tehokkuus heikkenee niukkafosforisella savella nopeammin kuin fosforitilaltaan keskinkertaisella savimaalla (Saarela et al. 2000). Maan liukoisen fosforin pitoisuuteen verrattuna sadot olivat edelleen runsaita. Vuonna 1999 kauran jyvien fosforipitoisuus oli kaikilla fosforilannoituksilla tavallista pienempi, vain $2.3-2.8 \mathrm{~g} / \mathrm{kg}$. Ohran jyvien fosforipitoisuus oli vuonna 2000 normaali eli 3.3-3.8 g/kg ja vuonna 2001 pienehkö eli $2.9-3.4 \mathrm{~g} / \mathrm{kg}$.

Taulukko 5. Vuosien 1992-1998 fosforilannoituksen, syksyllä 1998 syvämultauslaitteella 36 cm:n syvyyteen mullatun fosforin ja vuotuisen fosforin sijoituksen vaikutus kauran (1999) ja ohran (2000-2001) satoihin ja maan liukoisen fosforin pitoisuuteen (mg/l) syksyllä 2000 Jokioisten savimaalla.

\begin{tabular}{llllll}
\multicolumn{2}{l}{ Fosforilannoitus, taso tai } & $\mathrm{kg} / \mathrm{ha}$ & Jyväsato $\mathrm{kg} / \mathrm{ha}$ & Maan P syvyydessä \\
$1992-1998$ & syks. 1998 & Vuosittain & Ka 1999 Oh 2000 Oh 2001 & $0-18 \mathrm{~cm} \quad 18-36 \mathrm{~cm}$
\end{tabular}

$\begin{array}{lrrrrrrr}\text { Ei lainkaan } & 0 & 0 & 1530 & 3530 & 4370 & 0.8 & 0.6 \\ \text { Ei lainkaan } & 200 & 15 & 2960 & 4490 & 5860 & 1.4 & 1.1 \\ \text { Niukka } & 0 & 0 & 2060 & 3920 & 4690 & 0.9 & 0.7 \\ \text { Niukka } & 0 & 15 & 2500 & 4270 & 5550 & 1.1 & 0.8 \\ \text { Niukka } & 200 & 0 & 2930 & 4380 & 5670 & 1.4 & 1.6 \\ \text { Niukka } & 200 & 15 & 3130 & 4450 & 5520 & 1.3 & 1.5 \\ \text { Runsas } & 0 & 0 & 2570 & 4270 & 5280 & 1.5 & 0.9 \\ \text { Runsas } & 0 & 15 & 2970 & 4340 & 5780 & 1.7 & 0.9 \\ \text { Runsas } & 200 & 15 & 3030 & 4490 & 6250 & 2.5 & 1.5\end{array}$

\section{Johtopäätökset}

Juurten kasvulle edullisissa oloissa kuten hyvärakenteisilla ja kosteilla hietamailla kevätviljoilla tavallinen kylvölannoitus on sellaisenaan tehokas fosforin starttilannoitusmenetelmä. Olosuhteissa, joissa maan pinta pysyy orasvaiheessa märkänä, fosforilannoituksen hyväksikäyttöä voidaan tehostaa ja kasvien alkukehitystä parantaa sijoittamalla pieni määrä fosforia siemenriveihin tai niiden lähelle tavallista lannoitteen sijoitussyvyyttä matalampaan. Matala starttilannoitus on erityisen hyödyllistä silloin, kuin maan liikamärkyys haittaa oraiden juurten syvyyskasvua. Kuivissa oloissa lannoiterivien juurtumista sekä oraiden fosforin saantia ja kasvua voidaan edistää jyräämällä tai tiivistämällä lannoiterivit jyräpyörillä. Savimailla fosforin sijoittaminen siemenriviin näyttää soveltuvan hyvin syysviljoille, joiden starttilannoitusta kannattaisi tutkia muillakin maalajeilla. Jäykillä savimailla fosforin multaaminen tavallista kyntöä syvemmäksi pienentää kasvien riittävään fosforin saantiin tarvittavaa maan pinnan liukoisen fosforin pitoisuutta ja parantaa viljasatoja kuivina kasvukausia.

\section{Kirjallisuus}

Saarela, I. 1996. Tarkennettu fosforin sijoitus. Agronova 96, Hyvinkää, poster-esitys.

MTT, Jokioinen, mimeogr., 13 p.

Saarela, I., Kakkonen, K. \& Salo, Y. 2000. Savimaan fosforin saatavuuden parantaminen runsaalla kalkituksella sekä ruokamullan ja fosforin syvämultauksella. MTT:n julkaisuja, Sarja A 87.51 p. + 8 app.

Saarela, I, \& Saarela, K. 2000. Mapping spatial variation of diffusible soil P by in situ colouring in Fe-oxide paper. Commun. Soil Sci. Plant Anal. 31: 2019-2035. 